\title{
Gerência intercultural, diferença e mediação nas empresas transnacionais
}

\author{
Lívia Barbosa* \\ Letícia Veloso**
}

\section{Introdução}

Este artigo tem como objetivo trabalhar a idéia de interculturalidade no contexto de empresas transnacionais, a partir do desenvolvimento de uma noção específica de cultura e de contato intercultural (Barbosa e Veloso, 2006).

As empresas transnacionais apresentam características específicas em relação às chamadas empresas multinacionais e/ou globalizadas. O próprio

* Doutora em Antropologia, Ppgas, Museu Nacional, Pesquisadora do Centro de Altos Estudos em Propaganda e Marketing da Espm/SP e professora de antropologia da UFF. Autora dos livros Cultura, Consumo e Identidade, Rio de Janeiro, Ed. FGV, 2006 (em parceria com Colin Campbell, professor da University of York, England); Sociedade de Consumo, Rio de Janeiro, Editora Zahar, 2004; Cultura e Empresas, Rio de Janeiro, Jorge Zahar Editor, 2002; Igualdade e Meritocracia: a Ética do Desempenho nas Sociedades Modernas, Rio de Janeiro, Ed. FGV, 1999. E-mail: livia@visualnet.com.br

** Mestre e Doutora em Antropologia pela University of Chicago, Professora da Espm/RJ e pesquisadora do Centro de Altos Estudos em Propaganda e Marketing da Espm/SP. E-mail: lveloso@espm.bre1_veloso@terra.com.br

\begin{tabular}{|l|l|l|l|l|l|}
\hline Civitas & Porto Alegre & v. 7 & n. 1 & jan.-jun. 2007 & p. 59-85 \\
\hline
\end{tabular}


termo sinaliza a idéia de "atravessamento" do espaço nacional pela empresa, e não apenas a sua presença em vários países, como indicam os outros dois conceitos. Concretamente, a transnacionalidade da empresa implica em estratégias e políticas corporativas diferenciadas que vão desde um board de diretores composto por pessoas de diferentes nacionalidades, e não apenas por executivos do país original da empresa, passando por centros diferenciados de produção do conhecimento, por processos de compra e de recrutamento globalizados ou regionalizados, até a existência de uma forte cultura organizacional. Na verdade, esta última é que proverá a unidade simbólica e de objetivos para os indivíduos cultural e socialmente diferentes que integram as organizações transnacionais (Douw, 2002; Grewlich, 1981; Pitelis ; Kumar, 1997).

O conceito de interculturalidade, da maneira como hoje é articulado no discurso das empresas transnacionais - tanto do ponto de vista de seus programas institucionais, quanto na fala de seus executivos - diferencia-se do conceito de multiculturalidade (ou multiculturalismo). Este último conceito multiculturalismo - surgiu para dar conta das demandas dos novos movimentos sociais que, num mundo globalizado, percebiam não serem mais as questões sócio-econômicas que guiavam o debate político, e sim as demandas por reconhecimento cultural e identitário (Taylor, 1994; Taylor e Gutman, 1994; Willet, 1998). Muito em voga no momento, tanto na esfera política como na própria esfera organizacional, a noção de multiculturalismo vai além das políticas identitárias, pois elabora as questões da diferença e da identidade sob a rubrica do "reconhecimento" da diferença. Este conceito inclui não só identidades pessoais, mas também temas mais abrangentes como as políticas multiculturais, os dilemas éticos relacionados à diversidade cultural e étnica, os conflitos interculturais e a questão da integração (individual e social) a novas comunidades políticas multiculturais e transnacionais (Ong, 1999).

Enquanto o conceito de multiculturalidade enfatiza a coexistência de vários diferentes no interior de um mesmo espaço e ao mesmo tempo, sem a necessidade de interação, com uma interação limitada ao mínimo necessário para a operação da vida cotidiana ou, ainda, circunscrita à dimensão pública e jurídica, o conceito de interculturalidade enfatiza o oposto: que a "comunicação" entre os diferentes que habitam um mesmo espaço ao mesmo tempo se dá pela necessidade do estabelecimento de uma base comunicacional comum, a partir de sua mútua compreensão a respeito do que, naquele determinado 
contexto, deve ser o centro da comunicação. No caso específico das empresas transnacionais, o que está no centro da comunicação são os objetivos do negócio e a melhor forma de atingi-los.

Esta concepção da interculturalidade tal como esse conceito é operacionalizado hoje no universo das organizações transnacionais nos remete às teses de Habermas sobre a esfera pública e a possibilidade da compreensão pelo diálogo, tal como desenvolvidas em sua obra Teoria da ação comunicativa e, mais tarde, reelaboradas em seus trabalhos sobre as mudanças estruturais na esfera pública (Habermas, 1984, 1987, 1989). Embora este autor não seja explicitamente citado no material por nós analisado - as discussões que aparecem em sites de treinamento para executivos expatriados e os discursos dos próprios executivos, de diferentes nacionalidades, a respeito do contato cultural, das diferenças e da melhor forma de lidar com ambos - seu conteúdo converge para as concepções de Habermas. Ou seja, esses discursos enfatizam a necessidade de se entender o outro de um ponto de vista cultural, para que o diálogo e a comunicação possam ser estabelecidos. Mais do que a própria comunicação e o entendimento, o argumento de Habermas prega a necessidade do "consenso" a ser estabelecido através da ação comunicativa. Segundo o autor, este consenso não apenas se constrói a partir da comunicação: na verdade, é ele que permite a própria existência de uma esfera pública (Habermas, 1987; 1989).

O interessante desta convergência são as novas questões que ela suscita a respeito da relação entre empresas e interesses nacionais, e também sobre as novas maneiras de se construir as idéias de diferença e de alteridade. Para Habermas, o "diálogo" para o bem comum ocorre na esfera pública, sendo sancionado e legitimado por seus diferentes atores, enquanto que na noção de interculturalidade proposta pelos atores organizacionais através dos sites de treinamento, este diálogo é transferido para o interior da organização, cujos interesses não precisão estar alinhados com os interesses dos diferentes países onde ela atua. Com isso, as tensões e os conflitos são transferidos para fora da organização, ou seja, colocam-se entre ela e os múltiplos interesses nacionais, criando conflitos de lealdades entre as empresas e as nacionalidades. Embora façam parte da problemática, estas questões não serão desenvolvidas nesse texto. Aqui, iremos centrar-nos na questão da gerência intercultural, ou seja, em analisar como está sendo construída, em diferentes níveis, por diferentes grupos e em diferentes tipos de empresas transnacionais, uma concep- 
ção da relação entre culturas, e da relação entre diferentes, baseada na "compreensão" do outro.

Este artigo se origina em um estudo mais amplo sobre o tema da interculturalidade e gestão em empresas transnacionais que neste momento está em sua terceira fase (Barbosa e Veloso, 2006). Este estudo foi organizado sob a forma de uma pesquisa empírica de caráter comparativo, que se baseou em três tipos de dados distintos. O primeiro deles foi o material que coletamos em sites de empresas de várias nacionalidades que apresentam textos e materiais para treinamento e preparação de executivos que irão atuar no exterior. $\mathrm{O}$ que se buscou analisar neste tipo de dado foram as representações sobre a diferença, as culturas, o encontro cultural e a melhor forma de realizá-lo para se obter o sucesso empresarial. O segundo tipo de dado a ser analisado é resultante de entrevistas realizadas com altos executivos de grandes empresas transnacionais, todos possuindo grande experiência prática em gerenciamento de grupos cultural e nacionalmente diversos. Por fim, o terceiro tipo de dado foi coletado a partir da observação de casos empíricos de encontro cultural, no âmbito do cotidiano empresarial, incluindo tanto os níveis gerenciais, como os da base da pirâmide organizacional. A observação foi complementada por entrevistas, realizadas no local de trabalho, com os participantes de situações de encontro cultural. Essas entrevistas tiveram como fio condutor a discussão das situações concretas observadas. A estratégia escolhida foi a de trabalhar primeiramente com os elementos discursivos explícitos relativos a todo o processo para, posteriormente, investir na dimensão implícita e concreta, relativa à prática da gerência intercultural. A confrontação entre estes dois níveis da realidade nos permitirá desvendar os mecanismos sociais em operação e os pressupostos mais recônditos a partir dos quais a alteridade, a diferença e o contato entre culturas são construídos, e "superados" através do diálogo, da comunicação e do consenso. Neste artigo, serão apresentados apenas os resultados da primeira fase da pesquisa, isto é, única e exclusivamente a análise da forma como os processos de gerência intercultural estão levados a cabo por meio dos sites de treinamento intercultural.

\section{Cultura e interculturalidade nas organizações}

Tradicionalmente, a noção de interculturalidade está ligada à idéia de tradução de uma cultura para outra. Essa noção tornou-se popular no âmbito 
dos negócios internacionais, a partir de meados da Segunda Grande Guerra Mundial, principalmente nos Estados Unidos, e seu uso está historicamente relacionado com a preparação de diplomatas e homens de negócios norteamericanos para trabalharem no exterior (Hall, 1960; Benedict, 1974).

Do ponto de vista epistemológico, os interculturalistas concebem a noção de cultura como sendo um código em que elementos não são sinais sonoros ou luminosos, mas comportamentos ou traços materiais, cujo significado, como em todo código, tem sempre uma única e mesma definição, isto é, o código só é inteligível porque os seus componentes encontram-se previamente definidos. Ao contrário da linguagem, o código não é capaz de produzir novos significados (McCracken, 1991), e é precisamente esta característica que permite sua "tradução": por exemplo, o uso do espaço, a etiqueta nos negócios, os "valores" tais como a feminilidade e a hierarquia, são traduzidos de um código para o outro, sempre a partir de definições previamente estabelecidas e que parecem não se alterar conforme o contexto, nem conforme os atores (Hofstede, 1985, 1988; Hall, 1986). A partir dessa concepção, o contato cultural pode ser mediado através de fórmulas ou receitas "culturais" que "sintetizam" povos e sociedades através de alguns traços básicos. E todo este conhecimento pode ser transmitido através de uma didática de manual do tipo "how to do business with..." ou "regras ou leis para ser bem sucedido em..." (Ambler, 2003; Medina Walker e Walker, 2002; Morrison e Conaway, 2006).

Entretanto, a partir da década de 1980, com o avanço da globalização, o contato intercultural, até então restrito aos segmentos sêniors das organizações e aos expatriados, expandiu-se e rotinizou-se, ao mesmo tempo em que sua complexidade passou a ser melhor percebida. Trabalhar em e com times "multiculturais" e operar em mercados culturalmente diversos são experiências que passaram a integrar o cotidiano organizacional, significando um diferencial competitivo para jovens gerentes, e sendo consideradas exigência básica para qualquer líder organizacional (Parker, 1995). ${ }^{1}$

A reboque desta nova realidade surgiram questões importantes de serem trabalhadas na esfera gerencial e de mercado, questões estas que as fórmulas tradicionalmente utilizadas não davam mais conta: $O$ que são diferenças

Um bom exemplo do que acabamos de dizer pode ser encontrado na literatura de negócios e em revistas do tipo Fast Track, Exame, Você S. A. etc. 
culturais? Como se apresentam e como lidar com elas? Quais os seus impactos nos negócios e como estes impactos influenciam as comunidades locais? Como preparar as pessoas para operar em um mundo "multicultural", e qual o papel da cultura organizacional neste cenário?

Tornou-se necessário não só o entendimento mais profundo do contato cultural, mas também da própria noção de cultura, cujo significado, no âmbito da gestão organizacional, sofreu grandes transformações (Barbosa, 2002). Da ênfase na cultura organizacional da década de 1980, cujos melhores representantes são os trabalhos de Schein (1986), Hofstede (1985) e Deal e Kennedy (1982), passando pela década de 1990, com a idéia da cultura como um ativo intangível (Nonaka e Takeuchi, 1997; Root-Bernstein, 2000), até o momento atual, no qual a cultura transformou-se em um recurso (Yúdice, 2004) e a diferença, em diferencial competitivo e fonte de criatividade, ocorreram grandes mudanças que não podem ser compreendidas através da idéia de tradução de um "código" em outro, nem da idéia de cultura como uma variável a ser gerenciada, manejada, ou modificada (Anthony, 1994).

De totalidade fortemente integrada, inclusiva e excludente, a cultura passou a ser vista, por antropólogos e cientistas sociais, como dotada de uma natureza pluralista, controversa, processual, desunida e fragmentada (Jameson, 1984; Friedman, 1990; Lash e Urry, 1987). Esta nova concepção teve reflexos na forma como a cultura é vista no contexto das organizações. A noção de diferença - até então tratada como algo traduzível ou assimilável por contextos mais amplos - ganhou foros de direito, principalmente a partir da eclosão dos movimentos multiculturais, na década de 1980. Passou-se a falar, por exemplo, no direito à diferença (Taylor, 1994), no "direito de ter direitos" (Alvarez, Dagnino e Escobar, 1995; Escobar e Alvarez, 1992), e no direito ao reconhecimento da contribuição de cada um ao todo social (Honneth, 1998, 2001). E, embora a discussão sobre este tema seja altamente controversa do ponto de vista político e social, a cultura de negócios tem sido capaz de metabolizá-la de forma a neutralizar todo o seu potencial disruptivo, permitindo, assim, que essa agenda social possa ser operacionalizada sem danos empresariais (Barbosa, 2002).

A cultura de negócios cria um universo simbólico baseado em fluxos de idéias, valores e imagens que definem os parâmetros que devem ser seguidos para a obtenção do sucesso empresarial no mundo contemporâneo. Como seu 
principal mecanismo de difusão, temos as chamadas "tecnologias gerenciais" que, ao serem introduzidas nas empresas através de treinamentos, atualizam seus integrantes em relação aos conhecimentos e valores indispensáveis a uma "boa e ética" atuação profissional. Embora as tecnologias gerenciais sejam mecanismos globalizantes, seus princípios e ensinamentos são sempre customizados em relação ao contexto das diferentes culturas e empresas. Se, por um lado, essas tecnologias gerenciais constroem uma base comunicacional comum, por outro, esta base é parcialmente desconstruída pelas mediações que são estabelecidas para que estas mesmas tecnologias possam ser aplicadas nas diferentes empresas e em seus contextos específicos (Barbosa, 2002).

Independentemente do processo de assepsia e customização empreendido pelo universo de negócios no processo de construção da alteridade e da diferença, o fato é que a idéia de reconhecer e valorizar a diferença integra hoje o repertório do universo corporativo. Do ponto de vista empírico, este processo assume diversas formas nas diferentes empresas. Algumas investem na diferença como uma fonte para a criatividade empresarial (3M, Apple). Outras, como uma demonstração da sua responsabilidade social, de seu comprometimento e de seu comportamento ético em relação à comunidade, ao meio ambiente e às minorias (Natura, Unilever, Bank of Boston, IBM). Outras, ainda, como parte do seu capital intangível (Microsoft). Entretanto, qualquer que seja a estratégia adotada, o papel das diversas concepções de cultura e de diferença, bem como o papel das peculiaridades das culturas nacionais, organizacionais e corporativas envolvidas nessas concepções, passaram a ser considerados fundamentais.

No caso brasileiro, devido à aceleração do processo de internacionalização das empresas nacionais (Cvrd, Gerdau, Petrobras etc.), esta reflexão se tornou mais do que necessária, imperiosa até (Fleury e Fleury s. d.), como indicado pelo recente episódio envolvendo a Petrobrás e os governos brasileiro e boliviano, e pela reação da sociedade brasileira ao episódio. Entretanto, no âmbito das ciências sociais, e particularmente da antropologia, esta reflexão tem sido bastante restrita. O maior número de pesquisas e trabalhos sobre o tema tem ocorrido no âmbito da administração, mas este último campo de estudos continua pautados pela noção de cultura como unidade homogênea e excludente (Weber, 2004; Freitas, 2000; Trevisan, 2001; Chou, 2006). 
$\mathrm{Na}$ pesquisa cujos resultados parciais aqui apresentamos, nosso objetivo é triplo: em primeiro lugar, buscamos analisar como a noção de interculturalidade está sendo construída hoje no âmbito das empresas transnacionais, a partir de diferentes esferas e atores. Em segundo, procuramos demonstrar como a adoção da perspectiva antropológica ilumina de forma diferenciada esta discussão, na medida em que contextualiza a idéia de cultura, de diferença e de contato intercultural. Por fim, ao trabalharmos de forma comparativa e com dados de diferentes naturezas e fontes, almejamos produzir uma análise que englobe o discurso e a prática, dimensões fundamentais para o entendimento do tema.

\section{Cultura e diferença no mundo contemporâneo}

A diversidade cultural é um fato intrínseco ao mundo contemporâneo. Da mesma forma, a percepção de que vivemos num mundo diverso e multicultural, composto de vários diferentes que ocupam um mesmo espaço, também é parte constitutiva deste mundo contemporâneo, globalizado e marcado pelo desencaixe de tempo e espaço (Giddens, 1991), ambos comprimidos ao extremo de suas possibilidades (Harvey, 1989). Tais fatos, não é difícil de se perceber, põem profundamente em cheque a utilidade do conceito de "cultura", tanto no sentido que a antropologia lhe dá habitualmente, como também nos sentidos que lhes são atribuídos pela sociedade, seja através dos movimentos sociais ou dos grupos mais intelectualizados da população, seja através das definições propostas pelas empresas transnacionais.

Do ponto de vista mais "tradicional" da antropologia, cultura refere-se a sistemas de significados compartilhados, através dos quais os diferentes grupos sociais compreendem e estruturam suas vidas individuais e coletivas, e o mundo material que os rodeia. Assim, a cultura seria aquilo que caracteriza os grupos sociais definidos em termos de sua especificidade, estando associados a uma sociedade e a um território. De acordo com essa visão, grupos diferentes ocupariam espaços distintos e seriam portadores de "culturas" particulares e únicas.

O que acontece, porém, com o conceito "tradicional" de cultura, num mundo em que virtualmente todos os grupos, todas as sociedades e todos os países são, por definição, "multiculturais", ou seja, são compostos de uma 
multiplicidade de culturas em estreito convívio num mesmo espaço? Hoje, as sociedades são vistas como portadoras de diferentes sistemas de diferenciação, os quais se baseiam em diversos referentes, tais como etnias, grupos religiosos, subculturas, estilos de vida etc. Isso leva à constituição de meios de vida e de formas de expressão profundamente diferentes no interior de uma mesma sociedade, embora seus membros também compartilhem sistemas de significados em comum em diferentes níveis e acerca de vários temas - alguns mais, outros menos transitórios. Essa multiplicidade de sistemas de diferenciação coletiva é reforçada pelo predomínio do pensamento liberalburguês, sob influência da doutrina que Macpherson (1964) chamou de "individualismo possessivo", segundo a qual homens e mulheres modernos privilegiam, acima de tudo, o poder de manterem seus próprios pontos de vista, de realizarem suas próprias escolhas. Tudo isto levaria a um fortalecimento de estilos de vida e de culturas muito diferentes entre si, embora ocupando o mesmo espaço social.

Mais importante, porém, é o fato de que, a todo instante, os próprios mecanismos de globalização expõem praticamente todos os indivíduos às diferenças culturais, a diferentes estilos de vida e de pensamento. E mais: os indivíduos e grupos produzem respostas diferentes ao contato com a diferença que se revela cada vez mais presente. Sendo a diversidade cultural um fato da vida contemporânea que se legitima pela própria ideologia liberal, todas as sociedades atualmente tentam aprender a lidar com as diferenças que, mais do que em qualquer outro momento histórico anterior, as constituem e definem. Ao contrário das soluções tradicionais para o dilema da diferença hierarquizá-la e assim inferiorizá-la, ou assimilá-la, dissolvendo-a (Todorov, 1993) - pode-se pensar que o mundo contemporâneo está se propondo a tarefa de preservá-la e equalizá-la.

Pensar a diferença como fator constitutivo da sociedade, e encontrar modos de acomodar tais diferenças sem, no entanto, perder algum grau de coesão e unidade, esse é o núcleo do que podemos chamar de "pensamento multicultural", ou mesmo de "teoria do multiculturalismo", teoria esta que, na verdade, já vem sendo desenvolvida por uma multiplicidade de autores há cerca de 15 anos (Blum, 1998; Fraser, 1998; Fraser e Honneth, 2003; Gutman, 1994; Honneth, 1998, 2001; Kymlicka, 1997, 2001; Taylor, 1994; Willet, 1998). 
O termo multiculturalismo começou a circular nos anos setenta, em países como o Canadá e a Austrália, sendo utilizado, então, como instrumento discursivo para forçar os governos a desenvolverem políticas mais adequadas às minorias culturais e ao pluralismo étnico que constituía a polis nestes países. Em seu uso comum, o termo referia-se à realidade da imigração, que teria trazido como conseqüência não antecipada a discriminação dos povos originários dos dois países por parte dos grupos imigrantes anglo-saxões. Através do uso da noção de multiculturalismo, buscava-se superar as políticas assimilacionistas em prol da manutenção das identidades culturais das minorias, para que estas pudessem ter orgulho de sua própria cultura e, ao mesmo tempo, manter a sensação de pertencimento ao todo nacional. Como doutrina política, então, o multiculturalismo defendia políticas de reconhecimento dos direitos, das identidades culturais das minorias, e do valor da diversidade cultural. Não é por acaso que dois dos mais conhecidos proponentes da teoria multiculturalista nas ciências sociais são canadenses: Will Kymlicka (1997, 2001) e Charles Taylor (1994).

Porém, para além da teorização, a origem política do termo permaneceu sendo a fonte principal de sua força, pelo menos durante os anos 1980 e início da década de 1990. No contexto do ativismo político, o termo tem fortes conotações emancipatórias, sendo usado como contraponto a termos como "racismo" ou "etnocentrismo". Este foi o sentido que predominou, principalmente nos Estados Unidos, nas árduas batalhas políticas que foram travadas em prol do tratamento "politicamente correto" de temas relativos às diferenças étnicas e culturas - por exemplo, nos currículos escolares.

Tudo indica que cada sociedade tende a privilegiar um ou outro destes pontos de vista, de acordo com seus pressupostos culturais, sociais, políticos e históricos. Assim, sociedades como a alemã, por exemplo, que recentemente vem se deparando de forma mais intensa com a diferença através das recentes ondas de imigração de pessoas oriundas de sociedades menos privilegiadas, como as da África ou do Oriente Médio, tendem a privilegiar a perspectiva de assimilação do "outro". Nesta perspectiva, enfatiza-se a necessidade de que o "outro", no caso o imigrante, aprenda os modos e costumes, as leis e as regras da sociedade alemã, e assimile os valores e práticas dessa sociedade que, por sua vez, se autodefine desta forma como "unitária", negando, em certo sentido, o fato da imigração. 
Outro modelo é o priorizado pelos Estados Unidos da América. Este é o modelo que poderíamos chamar de modelo de integração. Nessa perspectiva, não se exige (ou não se exigia) que o "outro" seja assimilado à cultura norteamericana, mas que seja integrado a ela. Integrar pressupõe um menor grau de diluição das diferenças, uma vez que se aceita que os valores e pressupostos básicos do indivíduo e/ou grupo sejam mantidos, desde que ele aceite, por sua vez, se integrar ao funcionamento estrutural da sociedade que o recebe.

Nenhum destes modelos, porém, é capaz de equacionar a questão da diversidade, de modo a manter o respeito e o reconhecimento da diferença, ao mesmo tempo em que constrói uma "comunidade imaginada" (Anderson, 1983) fundada, exatamente, no conjunto das diferenças ou na valorização da diferença como fator importante, e até determinante, de uma sociedade. Este seria o movimento crucial que possibilitaria o contato verdadeiramente multicultural, uma forma de relação social que privilegia o valor intrínseco da diferença e estabelece formas de comunicação e mediação entre as diferenças. O foco aqui estaria, portanto, na comunicação entre as diferenças, e não na necessidade de desconstruir as diferenças através da assimilação ou da integração de um pelo outro.

É sob este aspecto que devemos compreender as recentes elaborações que vêm sendo produzidas pela teoria social sobre o binômio diferença/unidade, tido como característico do momento multicultural que vivemos. Para alguns autores, lidar com a diversidade implica reconhecimento da diferença, sem a exigência de sua superação em prol da construção de algo comum. São representantes desta linha de pensamento os autores Taylor (1994), Kymlicka (1997, 2001) e Willett (1998), que defendem o valor intrínseco da diferença como o aspecto mais importante da sociedade multicultural. Sendo múltipla e diferenciada por natureza, argumentam esses autores, a sociedade multicultural deve reconhecer o valor do diferente enquanto diferente, ou seja, celebrar o próprio fato da diferença como aquilo que a define enquanto sociedade. No mundo contemporâneo, a identidade, a diferença cultural e, principalmente, a luta pelo reconhecimento da diferença cultural em seu valor único e intrínseco, definem as relações intra e inter-sociais. Em outras palavras, de acordo com esta literatura, reconhecer significa apenas aceitar a existência do outro, sem compromisso maior com o estabelecimento de sínteses entre os diferentes. Podemos dizer que este é o modelo que mais caracteriza a reflexão sobre interculturalidade "à americana", tal como o encontra- 
mos na análise dos dados colhidos junto às empresas de treinamento intercultural americanas.

Criticando os proponentes da diferença como valor intrínseco à "boa sociedade", Nancy Fraser e Axel Honneth vêm buscando produzir novas reflexões sobre a temática. Segundo esses autores, o reconhecimento da existência da diferença não é suficiente para que uma sociedade saiba como lidar com esta diferença (Fraser e Honneth, 2003). Para Fraser (1998), a dificuldade surge de um dilema profundo: como oferecer reconhecimento sem redistribuição de recursos e sem justiça social? Honneth (1998, 2001), por seu turno, propõe reunir sob a rubrica reconhecimento tanto os aspectos culturais, valorizados por Taylor (1994) e Kymlicka (1997, 2001), quanto um imperativo moral e ético que permita um maior grau de consenso e de unidade. Assim, embora partam de pontos de vista diferentes, em certa medida, os dois autores advogam a superação do mero reconhecimento da diferença em prol da construção de um todo comum, moralmente válido e justo (Zurn, 2003).

É importante notar que é o alemão Axel Honneth quem propõe o modelo de multiculturalismo que mais se assemelha aos modelos de interculturalidade que, não por coincidência, foram identificados em nossa pesquisa no discurso das empresas de treinamento alemãs. "Reconhecer" o outro, para Honneth, é estabelecer elos de mediação baseados na solidariedade, ou naquilo que Honneth chama de "estima social". Pressupõe-se, portanto, a idéia de laços morais entre os diferentes e, por conseqüência, a idéia de respeito pelo outro, que se sobrepõe às diferenças intrínsecas. Reconhecer o "outro", para Honneth, não é apenas reconhecê-lo em sua diferença, mas "estimá-lo" o bastante para construir com ele laços de solidariedade. Em resumo, Honneth propõe a "apreciação" do outro, em vez de sua simples "aceitação". Tal perspectiva valoriza, assim, não só o outro, mas principalmente a superação das diferenças para com o outro e o estabelecimento de um elo comum, de uma sociabilidade comum que abrange tanto o "eu" quanto o "outro".

Para Honneth, a abordagem de Taylor (1994) é falha, no sentido de que ela defende uma noção de identidade que remete a uma suposta natureza primordial, quase pré-social. Assim, diz o autor, Taylor correria o risco teórico de aproximar-se de uma forma de etnocentrismo que, em tese, poderia levar à hostilidade entre os primordialmente diferentes. Para Honneth, o importante é perceber que as fronteiras entre o "eu" e o "outro" nem sempre são 
tão claramente definidas quanto Taylor presume. Sendo assim, embora Taylor e Honneth assumam que a luta pelo reconhecimento do "outro" é fundamental para a constituição do mundo multicultural, a ênfase de Honneth no fato de que as fronteiras nem sempre são delimitadas seria o que permitiria, em última análise, a construção das intermediações e dos elos entre os diferentes que, segundo o autor, seriam as características mais positivas da multiculturalidade.

O multiculturalismo é, portanto, um movimento tanto político quanto social-teórico, que vai muito além da mera idéia de que, hoje, as sociedades são, por excelência, culturalmente diferenciadas, e que, portanto, é necessário aprender a lidar com a multiplicidade de diferenças. Se há várias vertentes e posições relativas a essa questão, gostaríamos de sugerir que a teorização de Axel Honneth (1998) permite perceber todo o verdadeiro potencial de uma sociedade multicultural, uma vez que, implicitamente e em última análise, o que o autor sugere é a construção de pontes entre diferentes - ou seja, de mediações interculturais. São precisamente estas construções que são o tema desse trabalho.

\section{Cultura, diferença e treinamento intercultural: os sites de empresas de treinamento}

No Brasil, ainda são poucas as empresas dedicadas especificamente ao treinamento intercultural via internet, ao passo que, no exterior, este mercado está em expansão. Num primeiro levantamento realizado, encontramos mais de 200 sites que foram produzidos por empresas especificamente direcionadas para o treinamento intercultural, por escolas de negócios e por outros tipos de organizações que oferecem esta forma de treinamento. Escolhemos focar nossa análise em materiais produzidos em países diferentes, para fins comparativos.

Como os Estados Unidos representam o maior mercado em treinamento intercultural, este país foi escolhido como primeira referência para a comparação com o treinamento que é oferecido no Brasil. Com relação à Europa, nossa escolha recaiu sobre o material produzido na Alemanha, por motivos que explicitaremos abaixo. $\mathrm{Na}$ análise apresentada a seguir, comparamos três modelos de treinamento intercultural: o americano, o alemão e o brasileiro. 
No caso dos Estados Unidos, foram examinados cerca de 30 sites, mas concentramos a análise em apenas cinco, selecionados entre as principais empresas do setor de treinamentos daquele país. A partir desse material, foi possível perceber a existência de um padrão comum, o qual passaremos a chamar de modelo norte-americano de treinamento intercultural. Este modelo possui algumas características específicas que permitem a identificação de quais são os conteúdos atribuídos às noções de "cultura", de "alteridade" e de "diferença" tal como utilizadas no treinamento de executivos e de gerentes expatriados.

O que se percebe de imediato no material norte-americano é uma naturalização da cultura norte-americana. Parte-se do pressuposto de que as formas como os norte-americanos agem, os códigos pelos quais se relacionam e os valores segundo os quais enxergam o mundo seriam os "normais". Em termos práticos, esse pressuposto implica ser sempre necessário explicitar em detalhes que o "outro" é diferente do "eu" americano. Desconsidera-se o fato de que certos padrões e valores dominantes na cultura norte-americana (tais como "pró-atividade"; igualdade e aversão a hierarquias rígidas; predomínio das relações impessoais mas amigáveis nos negócios; valorização da pontualidade e da eficiência no cumprimento de prazos etc.) não se apresentam da mesma forma em todas as sociedades, nem são, para muitas, os elementos mais enfatizados no cotidiano organizacional e de negócios. Assim, aqueles que não procedem de acordo com o modelo são implicitamente considerados "deficientes", na medida em que não seguem os padrões de comportamento que o "eu" americano percebe como naturais e universais.

São esses pressupostos que explicam por que, em todos os sites pesquisados, o treinamento intercultural sempre se inicia pela afirmação da diferença e da igualdade do outro: "ensina-se" aos executivos, primeiro, que o "outro" é diferente. Num segundo momento, "ensina-se" que, mesmo sendo diferente, o outro não é necessariamente "falho" ou "ruim". Num terceiro momento, "ensina-se" a tolerância em relação ao outro, e pede-se certo grau de "paciência" com tais diferenças. Em todos os sites analisados, há uma insistência em explicar aos executivos que determinadas culturas têm uma relação diferente com o tempo, por exemplo, e que nem todas têm a mesma preocupação com rapidez e eficiência que os americanos, nem presumem (tal como os americanos) que estas são características absolutamente imprescindíveis ao bom negócio. Na mesma linha, ao tratarem de culturas como as da 
América do Sul ou do Caribe, há sempre a preocupação, expressa num tom condescendente, de explicar que os executivos americanos devem ter em mente que "não é porque eles demoram tanto para realizar suas tarefas que são preguiçosos". Segundo o discurso contido nos sites, tais culturas têm uma relação diferente com o tempo, e é por isso que trabalham de modo mais "lento" do que os americanos. Mas, diz o discurso, isto não quer dizer (notese que é sempre necessário explicitar que a diferença não é negativa) que eles sejam piores: afinal, estando todos trabalhando dentro de um mesmo objetivo, todos têm o mesmo interesse em cumprir as tarefas; o que difere são as noções de "eficiência" e de "prazo".

A empresa Gmac Global Relocation Services, com sedes em cinco cidades dos Estados Unidos, um escritório em Londres e um em Singapura, talvez seja um dos casos mais ilustrativos do modelo de interculturalidade comum nos Estados Unidos. Em seu site, a Gmac enfoca o ponto de vista da organização e os ganhos que repatriamentos ou expatriamentos bem feitos trarão para a organização. Todo o processo de repatriamento é entendido de maneira instrumental e, no caso desta empresa, o "treinamento intercultural" se dá, basicamente, de acordo com o seguinte roteiro: (1) apresentação, ao executivo, de uma seleção das informações mais importantes acerca do país no qual ele irá se instalar; (2) apresentação de informações que tratam os países e suas culturas como se fossem objetos de mesma natureza e idênticos ("a Índia" ou "o Brasil"); (3) indicação de serviços especializados: caso o executivo seja enviado para um local percebido como "violento", receberá treinamento específico de "como manter-se seguro"; caso seja locado em uma cidade do interior "sem as comodidades da vida moderna", será treinado para "lidar com adversidades". A seguir, a reprodução de parte de um texto retirado do portfolio dessa empresa: ${ }^{2}$

Executivos trabalhando na Índia encontrarão vários desafios inerentes ao trabalho no contexto de uma cultura tão antiga [...]. A cultura indiana pode apresentar desafios para empregados de companhias cuja cultura corporativa defenda uma atitude de "just do it" ("simplesmente faça"). Por causa de seu respeito pela hierarquia, os indianos acham difícil agir sem a aprovação prévia de um gerente, porque fazê-lo poderia, inadvertidamente, causar embaraços ao gerente. De for-

2 http://gmac.globalrelocation.com; acessado várias vezes ao longo do primeiro semestre de 2006. 
ma semelhante, tomadas de decisão são outra fonte de frustração para gerentes expatriados, pois um trabalhador indiano sempre quererá utilizar o maior tempo possível para reunir toda a informação relevante antes de chegar a uma decisão $[\ldots]$.

Engarrafamentos de Gado na Hora do Rush: ... [O sucesso] na Índia, portanto, vai depender de o executivo manter a mente aberta em termos de trabalhar com colegas cujos pressupostos culturais e sobre negócios são diferentes, e também de que ele vá para a Índia com expectativas realistas [...]. Afinal, ficar preso num engarrafamento de gado na hora do rush fora de Nova Delhi ou Mumbai não precisa ser uma experiência frustrante.

Outro exemplo ainda mais claro desta suposta necessidade de superação de uma visão negativa inicial, bem como das comparações implícitas feitas entre a cultura americana (tida como a "norma") e as outras culturas (tidas como diferentes ou estranhas), é a empresa SoCoCo International, com sede nos Estados Unidos, mas com escritórios também na França: ${ }^{3}$

Se não estivermos preparados para o encontro com as diferenças culturais (...) é muito fácil, quando chegamos a um novo país, acharmos as regras e regulamentos locais absurdos, e categorizarmos as pessoas através de vários atributos negativos. O que seria considerado normal em um dado país ou situação pode rapidamente se tornar tolo ou não apropriado em um contexto cultural diferente. É de fato muito perigoso julgar um comportamento ou uma idéia até entendermos realmente os mecanismos que a explicam [...]. Daí a importância de aprendermos regras e costumes locais, mesmo que não concordemos totalmente com eles. Seguir determinadas regras de comportamento público não significa que precisemos integrá-las ao nosso modelo de referência pessoal, ou que precisemos aprová-las.

Percebemos nestes exemplos que o modelo norte-americano enfoca a dimensão instrumental do aprendizado, ou seja, a aquisição de códigos e de "receitas" que podem ser aplicados em qualquer contexto, desde que: (a) o executivo perceba que seus pressupostos não são compartilhados pelo outro, e que, portanto, (b) é necessário saber quais são os pressupostos do outro para que se estabeleça a comunicação intercultural. O objetivo aqui é evitar que a comunicação intercultural seja prejudicada pelos pré-conceitos que, supõe-se, todos os norte-americanos teriam ao considerar sua cultura como o modelo

3 www.sococo.com; acessado várias vezes ao longo do primeiro semestre de 2006. 
em relação ao qual todas as demais devem ser medidas. Assim, neste modelo de treinamento intercultural, a cultura é pensada como um conjunto de características superficiais (gestos, posturas, etiqueta, relação com os horários etc.) que podem ser "aprendidas" por meio de guias passo-a-passo, e que devem ser incorporadas pelos envolvidos na tarefa de gerenciar culturas diferentes. Neste contexto, tanto a interculturalidade como o treinamento intercultural são pouco mais do que a aplicação correta destas receitas e a transmissão de determinados "instrumentos culturais" que permitem ao "eu" atuar na sociedade e cultura do "outro".

Ao comparar o "modelo" norte-americano com modelos de treinamento intercultural europeus, constata-se diferenças fundamentais, principalmente em relação ao tipo de treinamento oferecido na Alemanha. Nos sites de treinamento alemães, a busca pela competência intercultural é justificada pelo reconhecimento da necessidade, na sociedade contemporânea, de se valorizar a diferença e aquele que é diferente. Em vez de um conjunto de "receitas" e "passos" que devem ser aprendidos pelo executivo para bem situar-se em relação ao outro, o que se percebe é a valorização da diferença como um direito moral de todo e qualquer indivíduo ou povo. Em vez do pressuposto implícito de que a cultura do "eu" é o modelo "normal" em relação a que todos devem ser comparados, no caso alemão enxerga-se uma preocupação em valorizar a especificidade do "outro".

O modelo alemão parece incorporar preocupações contemporâneas relativas à dimensão política do contato multicultural. Ou seja, nele a diferença é percebida como constitutiva da vida social, na medida em que enfatiza sempre o fato de que se deve reconhecer o valor de todos os seres humanos, independentemente de suas especificidades culturais. Mais ainda, faz parte deste reconhecimento a desconstrução dos próprios preconceitos, mas num sentido muito diferente do modelo norte-americano analisado acima. $\mathrm{O}$ pressuposto do modelo alemão é uma sociedade em que todos se percebem como diferentes mas igualmente valorizados em termos morais - afinal, todos compartilham de uma humanidade básica. O preconceito, assim, é desconstruído, não porque seria prejudicial aos negócios - como no caso norte-americano mas porque todos devem aprender a viver em paz dentro de uma sociedade que, por definição, é multicultural. 
A aplicação desta visão ao conteúdo do treinamento intercultural oferecido nos sites alemães torna-se visível através da ênfase no conhecimento mais aprofundado sobre o "outro", bem como na busca de semelhanças e preferências comuns, as quais podem ser trabalhadas em conjunto para enriquecer a comunicação intercultural. Por exemplo, o site "World Experts", em sua filial alemã, diz: ${ }^{4}$

Entender o que o outro diz não significa necessariamente saber o que ele quer dizer. Sem o conhecimento sobre as especificidades culturais e sociais de um país torna-se difícil construir pontes e desconstruir preconceitos. Mesmo quando não conhecemos a língua do outro, o conhecimento e a compreensão dos valores culturais do outro permitem que possamos reconhecer e aceitar o outro.

A empresa afirma que seu objetivo primordial é fazer com que o aluno consiga:

ultrapassar o etnocentrismo (Ethnozentrismus), tornar-se atencioso [às necessidades] daqueles que lhe são estranhos, permitir uma adaptação seletiva aos valores e, com isto, facilitar a aculturação.

Diz, ainda, que isto é necessário porque, "apesar ou por causa da globalização", as especificidades culturais serão cada vez mais importantes. Portanto:

Tornar-se-á cada vez mais importante reconhecer as especificidades da própria cultura e das outras culturas e, na consciência da diferença, procurar aquilo que é comum.

Portanto, mais do que uma preocupação imediata com o sucesso dos negócios propriamente dito, o que se vê aqui é uma preocupação com a aceitação e com a superação de possíveis reações negativas, em prol de uma comunicação que respeite as diferenças. Isto porque, "sem o conhecimento das especificidades sociais e culturais de um país, torna-se difícil construir pontes e desconstruir preconceitos". Além disso, este material nos informa também que "a base para a comunicação intercultural bem-sucedida são a competência emocional e a sensibilidade intercultural". Sensibilidade esta que, como vimos acima, não se coloca como questão no modelo americano de gestão intercultural.

4 http://www.world-experts.de; acessado várias vezes ao longo do primeiro semestre de 2006. 
Os sites de treinamento intercultural alemães que foram pesquisados parecem utilizar-se da noção de diferença e do multiculturalismo para avançar na direção de um humanismo universal. Ou seja, vê-se aqui, implícita ou explícita, a idéia de que o reconhecimento da diferença não se dá apenas com base em identidades e especificidades culturais, mas tendo como pano de fundo um ideal universalizante, baseado na perspectiva humanista: reconhece-se o outro e aproxima-se deste outro, aceitando-o porque esta é a coisa moral e eticamente apropriada a se fazer. Uma visão que se aproxima da noção de imperativo moral, de onde devem partir todas as formas de reconhecimento.

Finalmente, com relação ao material brasileiro, constatamos a partir da análise comparativa dos sites que não existe ainda algo que se possa chamar de um "modelo brasileiro" de treinamento intercultural - o que aponta para o fato de existir um mercado a ser explorado, tanto academicamente quanto pelos negócios. Nos sites analisados, a maior parte do material relativo à questão do gerenciamento intercultural são traduções de materiais norteamericanos. Isso tem implicações, na medida em que, como já foi visto, o modelo norte-americano funda-se na naturalização da cultura norteamericana, e também porque o conteúdo destes sites não traduz a visão que muitas das empresas brasileiras atualmente passando por processos de internacionalização têm das questões envolvidas no gerenciamento intercultural. Mesmo assim, é possível discernir um certo esforço por parte dos produtores do material pesquisado, no sentido de adequá-lo ao contexto brasileiro.

Ao contrário do que prevalece no modelo norte-americano, o material brasileiro pressupõe a existência de uma diferença intrínseca entre o "eu" brasileiro e o "outro". Essa diferença não é naturalizada, no sentido de que o "eu" brasileiro seria o "normal", nem considerada em termos negativos ou pejorativos. O que se enfatiza é a compreensão dos pressupostos culturais que regem os outros universos sociais, para fins de mediação e conexão.

Dentre os poucos sites brasileiros sobre treinamento intercultural encontrados, foi possível perceber que as noções de cultura, diferença, interculturalidade e multiculturalismo tendem a não se encaixar nos sentidos que lhes são atribuídos no modelo alemão nem no modelo americano. Um site em especial, da empresa Living Internationally, talvez seja o melhor exemplo neste 
sentido. ${ }^{5}$ Em contraste com conteúdo dos sites americanos, cujo tom é sempre negativo e até mesmo "desconfiado", sendo sempre necessário demonstrar que o "outro" não é necessariamente ruim; e em contraste com o conteúdo dos sites alemães, que enfatizam sempre o teor político, ético e moral da interculturalidade, neste site o que se percebe é que as diferenças são aceitas e "abraçadas" de forma entusiasmada. Assim, por exemplo, diz-se que o treinamento é composto por sessões pré-mudança e pós-chegada, nas quais o indivíduo é levado a "perceber todo o potencial positivo daquele contato intercultural":

\section{Sessão pré-mudança:}

Permite aos que chegam:

Desenvolver conhecimento e habilidades para construir relacionamentos com os locais, nos negócios e em situações sociais.

Enxergar os próprios comportamentos, e aqueles dos locais, dentro de um contexto cultural. Adquirir competência e confiança na nova comunidade residencial.

Criar um plano de ação pessoal e familiar para extrair o melhor da nova locação.

\section{Sessão pós-chegada:}

Focalizada em gerenciar a vida cotidiana na cidade específica de transferência. Todas as questões relacionadas às preocupações e conforto do expatriado que chega ao novo país são abordadas. Os consultores: oferecem uma visão geral da cidade como residência e como centro comercial e cultural; discutem estratégias e táticas para navegar de melhor forma a cidade e seus desafios; oferecem materiais sobre a cidade aos quais todos deveriam ter acesso.

Ao longo do programa, a família recebe uma visão saudável, realista, e encorajadora da vida em sua nova cidade. Os tópicos tratados vão de vida noturna até questões cotidianas, de atividades esportivas até ajuda doméstica, de escolas até os direitos e deveres de locatários.

Além do teor positivo do texto, seu aspecto mais interessante é o compromisso com multiculturalismo como um valor: o material divulgado neste site afirma que o multiculturalismo é um fato concreto da vida cotidiana que traz como principal possibilidade a valorização das diferenças e a incorpora-

5 http://www.livinginternationally.com.br; acessado várias vezes ao longo de 2006. 
ção do que cada cultura teria de mais positivo. Visando promover o que seria uma percepção multicultural, o discurso deste site apresenta esta noção de multiculturalismo como definidora do modo de vida da sociedade contemporânea. A própria empresa se apresenta como estando em permanente mutação, tendo, desde 2006, incorporado o multiculturalismo e a valorização da diversidade como uma de suas prioridades (ibid.) Resta saber até que ponto tal incorporação consegue superar o nível do discurso e transformar-se em prática dentro da empresa, afetando, assim, o tipo de treinamento oferecido, bem como a noção de cultura na qual tal treinamento se baseia.

\section{Observações finais}

Uma vez que este artigo é resultado de uma pesquisa que ainda se encontra em andamento, à guisa de conclusão preferimos apontar algumas questões importantes que foram levantadas através da reflexão realizada até agora. Embora haja alguns sinais que apontam na direção da relativização e da desnaturalização, percebe-se claramente que no material recolhido nos sites norte-americanos predomina uma noção de cultura que há muito foi superada pela antropologia e pelas ciências sociais em geral. Esta noção remete a três pressupostos: em primeiro lugar, a idéia de cultura como algo homogêneo, sempre partilhado por todos dentro de um mesmo grupo e, portanto, não comportando questionamentos ou diferenças internas. Em segundo, e diretamente relacionado com o primeiro ponto, a cultura vista como algo necessariamente excludente - o "outro" é sempre aquilo que o "eu” não é. Em terceiro, e em decorrência lógica destes dois primeiros pontos, o pressuposto de que a cultura do "eu" é a "norma", o "natural", o "normal", enquanto a cultura do "outro", por ser definida como "não-eu", carrega necessariamente conotações negativas. De acordo com a mesma lógica, no material norteamericano, predomina uma noção de interculturalidade fundada nas regras de etiqueta, nas minúcias de posturas e comportamentos superficiais. Os executivos são treinados em relação a estes aspectos superficiais, pressupondo-se que, a partir deles, seria possível ao menos evitar os atritos presumidamente sempre produzidos por qualquer contato intercultural, causados principalmente pela tentativa de se aplicar padrões de comportamento distintos daquilo que o "eu" americano tenderia a perceber de forma negativa ou mesmo hostil. 
Já no caso alemão, o que percebemos foi a presença de uma dimensão política, de uma postura claramente dialógica. Percebe-se uma nítida preocupação com o reconhecimento, com a aceitação e a superação das diferenças como passos importantes em prol do consenso. É interessante notar que, como afirmamos acima, não encontramos menção explícita à obra de Habermas nem à de Honneth. Porém, o conteúdo do material reunido sob a rubrica "modelo alemão" parece ter afinidades com noções importantes no trabalho destes dois autores. Em sintonia com as idéias de Habermas, o discurso presente no material pesquisado expressa que, dentro ou fora da organização, a comunicação é a base do reconhecimento, da possibilidade, e mesmo da convivência em sociedade. E mais, o discurso afirma que esta comunicação deve ser marcada pelo diálogo entre os diferentes, pois é através deste diálogo que se pode produzir o tão esperado consenso. Já em relação à obra de Honneth $(1998,2001)$, os textos presentes nos sites apontam para a idéia de que o imperativo ético e moral é o que fundamenta e possibilita a comunicação dialógica e consensual entre os diferentes. As diferenças são aceitas por razões morais e éticas, mais do que pela necessidade de se conduzir bem os negócios. Para além do reconhecimento da diferença, o que se busca é o reconhecimento do valor moral de todos os diferentes.

Finalmente, em relação à análise do modelo brasileiro (que só foi possível esboçar nesse trabalho), gostaríamos de ressaltar um ponto principal, referente à própria escassez de material sobre treinamento intercultural produzido no país. Sugerimos que este, em si, já pode ser tomado como um dado relevante, na medida em que os Estados Unidos e Alemanha (e diversos outros países) vêm se ocupando sobremaneira com este tema e produzindo abundantemente materiais sobre ele. Por que exatamente haveria tal silêncio relativo no caso brasileiro? Num primeiro momento, imaginamos que esse seria o resultado de uma "colonização cultural," por assim dizer: os brasileiros estariam importando materiais norte-americanos e os utilizando sem questionar seus pressupostos. Assim, embora estivessem se internacionalizando cada vez mais, as empresas brasileiras não estariam sendo capazes de produzir materiais que objetivassem o aprendizado das diferenças, aprendizado este que é constitutivo do próprio processo de internacionalização.

Mas podemos levantar outra hipótese: a pouca preocupação com a diferença entre o "eu" e o "outro" demonstrada por empresas brasileiras pode também ser compreendida como fruto de uma ideologia igualitária e consen- 
sual acerca do espaço da diferença que, sugerimos, ainda predomina na sociedade brasileira. Como bem demonstrou DaMatta (1989), a sociedade brasileira se percebe como profundamente igualitária e hábil na transposição das diferenças em prol do consenso. Não se trata do não-reconhecimento da diferença, mas sim de tomar a diferença como um dado intrínseco à própria sociedade, e de lidar com ela através do estabelecimento de mediações e de consensos fundados no reconhecimento de uma suposta igualdade comum. Sob este ponto de vista, podemos avançar a análise aqui proposta, sugerindo que é exatamente esta ideologia que, potencialmente, poderia levar à construção de um "modelo" de interculturalidade à brasileira. Este modelo seria ainda mais dialógico e consensual do que o modelo alemão e, portanto, mais apto a lidar com as diferenças de uma forma ainda mais complexa. Isto porque existe, nesta ideologia que a sociedade brasileira construiu acerca de si própria, um potencial até agora pouco explorado para o diálogo e consenso (DaMatta, 1989), a partir de noções fundadas precisamente numa suposta igualdade comum subjacente a todas as diferenças superficiais. E seriam exatamente estas noções mais complexas - e ainda por construir - que, sugerimos, poderiam contribuir para a construção, precisamente, do tipo de mediação intercultural que havíamos visualizado ao iniciarmos esta pesquisa.

\section{Referências}

ALVAREZ, Sonia; DAGNINO, Evelina; ESCOBAR, Artur (Orgs.). Cultures of politics, politics of cultures: re-visioning Latin American social movements. Boulder: University of Colorado Press, 1995.

AMBLER, Tim. Doing business in China. New York: Routledge and Curzon, 2003.

ANDERSON, Benedict. Imagined communities. London: Verso, 1983.

ANTHONY, Peter. Managing culture. Londres: Open University Press, 1994.

APPADURAI, Arjun. Modernity at large. The cultural dimensions of globalization. Minneapolis: Minnesota University Press, 1996.

BARBOSA, Lívia. Cultura e empresas. Rio de Janeiro: Zahar, 2002.

BARBOSA, Lívia. Globalização e cultura de negócios. In: KIRSCHNER, Ana Maria; GOMES, Eduardo R.; CAPPELLIN, Paola (Orgs.). Empresas, empresários e globalização. Rio de Janeiro: Relume Dumará, 2002. 
BARBOSA, Lívia; VELOSO, Letícia. Relatório final de pesquisa sobre gerenciamento intercultural. São Paulo: Centro de Altos Estudos em Propaganda e Marketing, Espm/SP, 2006.

BHABHA, Homi. Anxiety in the midst of difference. Polar: Political and Legal Anthropology Review, v. 21, n. 1, p. 123-137, 1998.

BENEDICT, Ruth. O crisântemo e a espada. Padrões de cultura japonesa. São Paulo: Perspectiva, 1974.

BERGER, Peter; HUNTINGTON, Samuel. Muitas globalizações: diversidade cultural no mundo contemporâneo. São Paulo: Record, 2004.

BLUM, Lawrence. Recognition, value, and equality: a critique of Charles Taylor's and Nancy Fraser's accounts of multiculturalism". In: WILLET, Cynthia (Org.). Theorizing multiculturalism: a guide to current debate. Oxford: Blackwell Publishers, 1998.

CHOU, Renata A. Contribuições à compreensão da gestão à brasileira. Dissertação de Mestrado. São Paulo: Escola de Administração de Empresas, FGV, 2006.

DaMATTA, Roberto. A casa e a rua. Rio de Janeiro: Guanabara, 1987.

DAUW, L. Rethinking chinese transnational enterprise. 2002.

DEAL, Terrence E.; KENNEDY, Allan A. Corporate cultures. Maddison: Wesley, 1982.

ESCOBAR, Arturo; ALVAREZ, Sonia (Orgs.). The making of social movements in Latin America: identity, strategy, and democracy. Boulder: University of Colorado Press, 1992.

FLEURY, A.; FLEURY, Maria Tereza. Understanding the challenge of late-movers. Internationalization processes: the Brazilian Case. s. d., Mimeo.

FRASER, Nancy. From redistribution to recognition? Dilemmas of justice in a 'postsocialist' age. In: WILLET, Cynthia (Org.). Theorizing multiculturalism: a guide to current debate. Oxford: Blackwell Publishers, 1998.

FRASER, Nancy; HONNETH, Axel. Redistribution or recognition? A politicalphilosophical exchange. London: Verso, 2003.

FREITAS, Maria Ester. Como vivem os executivos expatriados e suas famílias. Relatório de Pesquisa, n. 7, Easp/FGV/NPP. São Paulo, 2000.

FRIEDMAN, Jonathan. Globalization and localization. In: FEATHERSTONE, Mike (Org.). Global culture. London: Sage, 1990.

GREWLICH, Klaus. Transnational enterprises in a new international system. London: Springer, 1981.

GIDDENS, Anthony. As consequências da modernidade. São Paulo: Unesp, 1991. 
GUTMAN, Amy (Org.). Multiculturalism: examining the politics of recognition. Princeton: Princeton University Press, 1994.

HABERMAS, Jürgen. Consciência moral e agir comunicativo. Rio de Janeiro: Tempo Brasileiro, 1989.

—. Teoria de la acción comunicativa. Madrid: Taurue, 1987.

1984.

HALL, Edward. A dimensão oculta. Rio de Janeiro, 1960.

- The silent language in overseas business. Harvard Business Review, MayJun., 1960.

HARVEY, David. The condition of postmodernity. Cambridge: Blackwell, 1989.

HONNETH, Axel; ANDERSON, Joel. The struggle for recognition: the moral grammar of social conflicts. Cambridge: MIT Press, 1998.

HONNETH, Axel. Recognition or redistribution? Changing perspectives on the moral order of society. Theory, Culture, \& Society, v. 18, n. 2-3, p. 43-55, 2001.

HOFSTEDE, Geerdt. e BOND, M. H. The confucius connection: from cultural roots to economic growth. Organizational Dynamics, v. 16, n. 4, p. 4-21, 1998.

HOFSTEDE, Geerdt. Culture's consequences. International differences. In: Workrelated values. Beverly Hills: Sage, 1985.

JAMESON, Frederic. Pós-modernismo: a lógica cultural do capitalismo tardio. São Paulo: Ática, 1984.

KUMAR, Krishan. Da sociedade pós-industrial à pós-moderna: novas teorias sobre o mundo contemporâneo. Rio de Janeiro: Jorge Zahar, 1997.

KYMLICKA, Will. Multicultural citizenship: a liberal theory of minority rights. Oxford: Oxford University Press, 1997.

- Politics in the vernacular: nationalism, multiculturalism, and citizenship. Oxford: Oxford University Press, 2001.

LASH, Scott; URRY, John. The end of organized capitalism. Cambridge e Oxford: Polity and Blackwell, 1987.

LASH, Scott e FEATHERSTONE, Mike (Orgs.). Recognition and difference: politics, identity and multiculture. Londres: Sage, 2001.

MACPHERSON, Crawford. The political theory of possessive individualism: Hobbes to Locke. Oxford: Oxford University Press, 1964.

MCCRACKEN, Grant. Culture and consumption. New approaches to the symbolic character of consumer goods and activities. Indianapolis: Indiana University Press, 1991. 
MARTIN, Bill. Multiculturalism? Consumerist or transformational? In: WILLET, Cynthia (Org.). Theorizing multiculturalism: a guide to current debate. Oxford: Blackwell Publishers, 1998.

MATUSTÍK, Martin J. B. Ludic. Corporate, and imperial multiculturalism: impostors of democracy and cartographers of the new world order”. In: WILLET, Cynthia Willet (Org.). Theorizing multiculturalism: a guide to current debate. Oxford: Blackwell Publishers, 1998.

MEDINA-WALKER, Danielle; WALKER, Thomas. Doing business internationally, second edition. A guide to cross-cultural success. New York: MacGraw Hill, 2002.

MORRISON, Terri; CONAWAY, Wayne. Kiss, bow, or shake hands. The bestselling guide to doing business in more than 60 countries. Second edition. New York: Adams, 2006.

NAVA, Mica. Cosmopolitan modernity: everyday imaginaries and the register of difference. Theory, Culture, \& Society, v. 19, n. 1-2, p. 81-99, 2002.

NONAKA, I.; TAKEUCHI, H. Criação de conhecimento na empresa. Como as empresas japonesas geram a dinâmica da inovação. Rio de Janeiro: Campus, 1997.

ONG, Aihwa. Flexible citizenship. The cultural logics of transnationality. Durham: Duke University Press, 1999.

PITELS, Christon (Org.). The nature of the transnational firm. London: Routledge, 2000.

PARKER, G. O ooder das equipes. Um guia prático para implementar equipes interfuncionais de alto desempenho. Rio de Janeiro: Campus, 1995.

ROOT-BERNSTEIN, Robert S. Centelhas de gênios. São Paulo: Nobel, 2000.

SANTOS, Boaventura de Sousa. Pela mão de Alice: o social e o político na pósmodernidade. 4. ed. São Paulo: Cortez, 1997.

SANTOS, Boaventura de Sousa (Org.). Reconhecer para libertar: os caminhos do cosmopolitismo cultural. Rio de Janeiro: Civilização Brasileira, 2003.

SCHEIN, Edgar H. Organizational culture and leadership. San Francisco, Jossey Bass, 1986.

TAYLOR, Charles. The politics of recognition. In: GUTMAN, Amy (Org.). Multiculturalism: examining the politics of recognition. Princeton: Princeton University Press, 1994.

TAYLOR, Charles; APPIAH, Kwame Anthony; HABERMAS, Jürgen; ROCKEFELLER, Stephen C. Multiculturalism. Princeton: Princeton University Press, 1994.

TODOROV, Tzvetan. Nós e os outros. Rio de Janeiro: Jorge Zahar, 1993 
TREVISAN, L. Interculturalidade no ambiente empresarial: relações entre brasileiros e estrangeiros na Volkswagen/Audi de São José dos Pinhais - Paraná. Dissertação de Mestrado, Programa de Pós-graduação em Tecnologia, Centro Federal de Educação Tecnológica do Paraná. Curitiba, 2001.

TSING, Anna. The global situation. Current Anthropology, v. 15, n. 3, p. 327-360, 2001.

WEBER, R. A. A comunicação intercultural no ambiente de trabalho: a interação entre trabalhadores brasileiros e estrangeiros em empresas multinacionais no Brasil. Dissertação de Mestrado, Programa de Pós-Graduação em Engenharia de Produção da Universidade Federal de Santa Catarina. Florianópolis, 2004.

WILLET, Cynthia (Org.). Theorizing multiculturalism: a guide to current debate. Oxford: Blackwell Publishers, 1998.

YÚDICE, George. A conveniência da cultura. Usos da cultura na era global. Belo Horizonte: Editora da Ufmg, 2004.

ZURN, Christopher F. Identity or status? Struggles over 'recognition' in fraser, Honneth, and Taylor. Constellations, v. 10, n. 4, p. 519-537. 2003. 